\title{
Cost Effective Sensors for Automated Progress Measurement and Management (APMM)
}

\author{
Youngsoo Jung ${ }^{1 *}$, Jiwon $\mathrm{Ha}^{1}$, Taehwan $\mathrm{Ju}^{1}$, and Seunghee Kang ${ }^{2}$ \\ ${ }^{1}$ Department of Architecture, Myongji University, Yongin, Korea \\ ${ }^{2}$ CM Research Division, Korea Research Institute for Construction Policy, Seoul, Korea \\ *Corresponding author (yjung97@mju.ac.kr)
}

\begin{abstract}
Purpose 'Progress' is the most often used indicator in construction project management. Nevertheless, excessive management efforts to collect and analyze detailed data have been highlighted as a major barrier for advanced progress management techniques for construction projects. Even though the advent of data acquisition technologies (DATs) provides for automated manipulation of these requirements, previous research efforts have mainly focused on a specific DAT or on the limited construction tasks. In order to effectively utilize DATs for construction projects, a comprehensive approach is desirable, possibly including every single work item within the automated system. The purpose of this paper is to propose such a methodology for integrated utilization of DATs for repeated applications to multiple work items. Method For the purpose of selecting the most adequate DATs for the most frequent patterns of automated data acquisition methods, we first evaluated a comprehensive evaluation of entire work items for a case-project. The criteria for this selection process are modified and simplified based on the algorithm developed by Kang and Jung. Secondly, DAT candidates for most frequent data acquisition patterns were then systematically examined in order to maximize the benefits of utilizing DATs for construction progress measurement. Results \& Discussion We found that the most promising area for automated progress measurement and management (APMM) is to deploy 'simplified and low-cost sensors' for monitoring the 'entrance and exit' of 'labors' into a locator of 'floor (story)' level for a building construction. The rationale, techniques, and implications of the proposed methodology are illustrated by a case-project. Recommendations for future research are also discussed.
\end{abstract}

Keywords: data acquisition technology (DAT), automated progress measurement, sensor, scheduling

\section{INTRODUCTION}

Cost, schedule, and quality are the three major indicators for successful construction projects. Monitoring these three indicators provides the managers with valuable information in terms of 'current status', 'corrective countermeasure', and 'forecast of future risks'. However, the managerial effort (or workload) required to acquire and maintain detailed progress data has been the major barrier to practical implementation $^{2}$. Even though the advent of data acquisition technologies (DATs) provides an automated way to manipulate these requirements, previous research efforts have mainly focused on a specific DAT or on the limited construction tasks. In order to effectively utilize DATs for construction projects, a comprehensive approach possibly including every single work item within this automated system is desirable. Nevertheless, to date, there have been very limited research efforts comprehensively addressing a methodology in order to integrated and optimize the automated tools for effective progress management. In this context, the purpose of this paper is to propose a methodology for integrated utilization of DATs by repeatedly applying the same sensors to multiple work items. For the purpose of selecting the most adequate DATs for the most frequent patterns of automated data acquisition methods, a comprehen- sive evaluation of entire work items for a caseproject was evaluated.

\section{Construction Progress MeAsurement}

The most commonly perceived concept of progress implies the "work completed with the associated cost". Therefore, progress can be defined as the "actual work completed in terms of budgeted cost" ${ }^{1}$. This progress (earned value, or budgeted cost for work performed, EV or BCWP) is used as a baseline to which the planned schedule (budgeted cost for work scheduled, PV or BCWS) and the actual cost (actual cost of work performed, AC or ACWP) are compared to measure the schedule performance and cost performance, respectively. In an effort to automate the progress measurement process, Jung and $\mathrm{Kang}^{1}$ proposed a concept of standard progress measurement package (SPMP) that enables automated generation of WBS with standard packages and methods based on historical project database and knowledge (Column (a) through (d) in Table 1). One of the distinct characteristics of the SPMP is that each progress measurement package (PMP) has automatically embedded properties specifying the most appropriate types of measurement locator (physical breakdown, e.g. one floor), measurement complexity, and most likely duration. It also evolves as a project's requirements are changing. The case- 
project in Table 1 is a research complex. Specifics of the case-project include: an eleven-story office building and a laboratory, $17,087 \mathrm{~m}^{2}$ of total floor area, 19-month project duration.

\section{DATA ACQUISITION TECHNOLOGY (DAT)}

Various research efforts have been conducted in order to utilize advanced data acquisition technologies (DATs) in construction. A comprehensive literature survey ${ }^{8}$ investigating DAT applications in construction over fifteen year period (1993 through 2008) found that $47.3 \%$ of DAT applications were for 'concrete works' and $25.0 \%$ for 'earthwork' among many different work sections. In terms of DAT, RFID (36.1\%) and GPS (33.3\%) are the most often used technologies. As for construction business functions, scheduling $(30.7 \%)$ was the most popular area for DAT utilization as illustrated in Figure 1. It is also observed that recent researches in photogrammetry and automated pattern recognition are widely exerted. However, these technologies are still under developing and hardly satisfy technical and economic feasibility. Another important notion is that previous studies addressed specific DAT or on the limited construction tasks (e.g. GPS application for earthwork). The objects, from which the automated DAT applications collect data, can be categorized into four types, including labor, material, equipment, and document. The survey by Seo et al. ${ }^{8}$ indicated that frequency for material, equipment, and labor as DAT objects were $47.6 \%, 29.2 \%, 23.0 \%$, respectively. Among these measuring objects, the labor information is promising area for repeated DAT application for multiple work packages because every work package heavily depends on workers. Nevertheless, previous researches require identifying the locations of specific trades or crews in order to control labor information. For example, Navon and Goldschmidt ${ }^{5,6}$ proposed automated labor monitoring frameworks for automated project performance control which incorporates planning, design, and project control data. Sacks et al. ${ }^{7}$ further developed a labor monitoring system by attaching GPS receivers to labors' helmets. In order to maximize the benefits from DAT, this study attempts to develop a low-cost sensing system for multiple operations to many different work packages within a project.

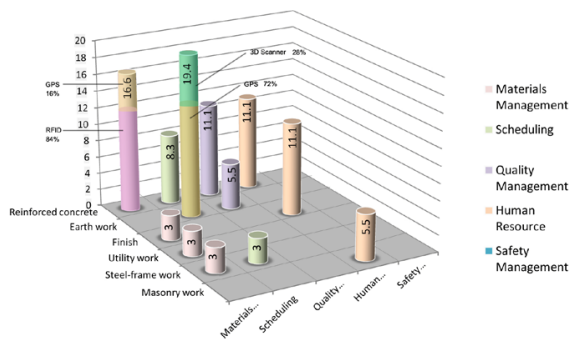

Fig. 1. DAT Applications in Construction Literature (Seo et al. 2009)
Automated Progress Measurement (APMM)

A series of research efforts for automated progress measurement and management (APMM) has been conducted at Myongji University in Korea. This paper is part of consecutive researches as described in Figure 2.

The first step was automating work breakdown structure (WBS) generation. It was found that standardized WBS can be automatically generated by using historical database and construction knowledge ${ }^{1}$. It was of great importance in practice because less experienced engineers on the job site have difficulties in formulating WBS, and WBS is a starting point for progress measurement for any project ${ }^{1,3}$.

The second step was developing a methodology to automatically assign most appropriate measurement method (e.g. physical measurement, earned value, estimated percent complete) to each work package ${ }^{1}$. The result from these two automated steps is shown in Column (a) through (d) in Table 1.

After automatically generating the work packages with assigned measurement methods (PMPs in Table 1), as the third step, it is necessary to assign most effective DAT to every single work package. Kang and Jung $^{4}$ developed a methodology in order to automate this DAT evaluating and assigning process. The characteristics of PMPs and DATs are organized in a structured manner so that knowledge can be accumulated for DAT selection ${ }^{4}$. Column (e) through (h) in Table 1 lists the result of this automated DAT selection process.

Finally, the fourth step is to identify work packages (PMPs) those can share the same DAT application for repeated utilization.

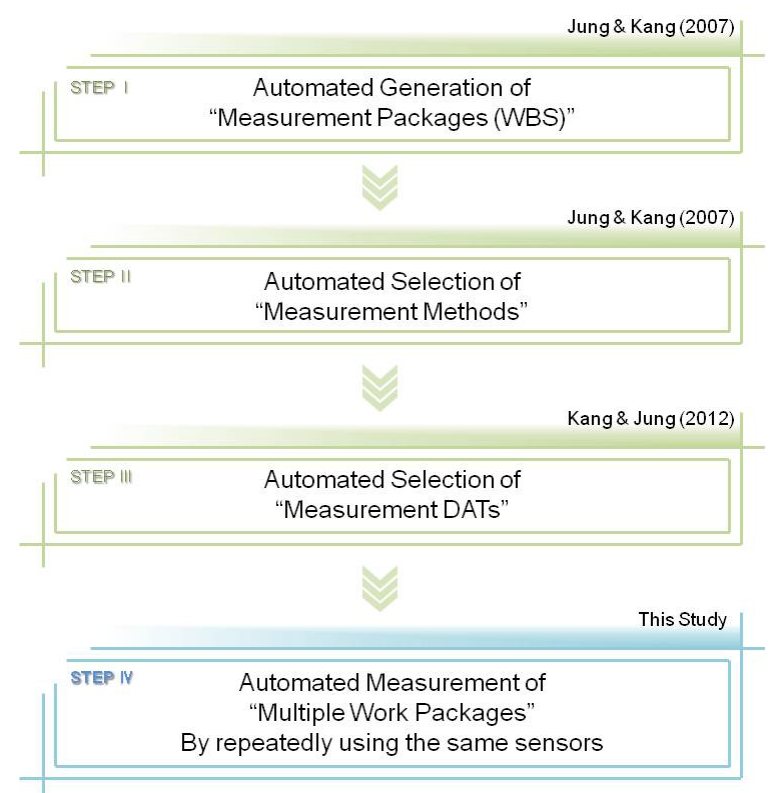

Fig. 2. Automated Progress Measurement and Management (APMM) Research at Myongji University 
Table 1. Result of automated PMP generation ${ }^{1}$ and automated DAT selection for a case-project ${ }^{4}$

\begin{tabular}{|c|c|c|c|c|c|c|c|}
\hline \multirow[t]{2}{*}{ (a) ID } & \multirow{2}{*}{$\begin{array}{l}\text { (b) Measurement Package } \\
\text { (PMP) }\end{array}$} & \multicolumn{2}{|c|}{ Characteristics } & \multicolumn{4}{|c|}{ Automated Data Acquisition Method } \\
\hline & & (c) Locator & (d) Duration & (e) Object & (f) Range & (g) Data & (h) DAT \\
\hline BB10 & Excavation \& Fill & A section & $1 \mathrm{mo} \leq \mathrm{D}<2$ & Equipment & Gate & In \& Out & RFID \\
\hline $\mathrm{BC} 10$ & Scaffolding and Temporary & One building & $\mathrm{D} \geq 2 \mathrm{mos}$ & Document & $\mathrm{N} / \mathrm{A}$ & Quantity & Report \\
\hline BC3010 & Cast-In-Place Concrete & One floor & $D<1 w k$ & Equipment & Gate & In \& Out & RFID \\
\hline BC3020 & Formwork & One floor & $D<1 w k$ & Material & Locator & Trajectory & GPS \\
\hline BC3030 & Reinforcing Steel & One floor & $D<1 w k$ & Labor & Locator & Trajectory & GPS \\
\hline BC40A & Plant-Precast Concrete & One floor & $1 w k \leq D<2$ & Material & Locator & Trajectory & GPS \\
\hline BC5010 & Structural Steel & An assemble & $1 \mathrm{mo} \leq \mathrm{D}<2$ & Material & Gate & In \& Out & RFID \\
\hline BC5020 & Steel Erection & An assemble & $D<1 w k$ & Material & Locator & Trajectory & GPS \\
\hline BC5030 & Steel Deck & One floor & $D<1 w k$ & Material & Locator & Trajectory & GPS \\
\hline BC60A & Brick Masonry & Two floors & $1 w k \leq D<2$ & Labor & Locator & In \& Out & RFID \\
\hline BC60B & CMU & One floor & $1 w k \leq D<2$ & Labor & Locator & In \& Out & RFID \\
\hline BD10 & Roofing Accessories & Project & $\mathrm{D}<1 \mathrm{i} \mathrm{wk}$ & Document & N/A & Quantity & Report \\
\hline BE20A & Cementitious Waterproofing & One floor & $D<1$ wk & Labor & Locator & In \& Out & RFID \\
\hline BE20B & Sheet Waterproofing & One floor & $2 w k \leq D<1$ & Labor & Locator & In \& Out & RFID \\
\hline BE20C & Fluid-Applied Waterproofing & One floor & $D<1 w k$ & Labor & Locator & In \& Out & RFID \\
\hline BE20D & Special Waterproofing & One floor & $1 w k \leq D<2$ & Labor & Locator & In \& Out & RFID \\
\hline BE20F & Joint Sealants & One floor & $D<i w k$ & Labor & Locator & In \& Out & RFID \\
\hline BE2505 & Cement Plaster (Interior) & One floor & $1 w k \leq D<2$ & Labor & Locator & In \& Out & RFID \\
\hline BE2510 & Cement Plaster (Exterior) & One floor & $1 w k \leq D<2$ & Labor & Locator & Out & RFID \\
\hline BE2515 & Cement Plaster (Floor) & One floor & $\mathrm{D}<\dot{i} w \mathrm{k}$ & Labor & Locator & In \& Out & RFID \\
\hline BE2530 & Cement Plaster (Stair) & A stairwell & $1 \mathrm{mo} \leq \mathrm{D}<2$ & Labor & Locator & In \& Out & RFID \\
\hline BE2535 & Coatings for Concrete & Two floors & $D<1 w k$ & Labor & Locator & In \& Out & RFID \\
\hline BE2540 & Concrete Finishing & One floor & $D<1 w k$ & Labor & Locator & In \& Out & RFID \\
\hline BE2545 & Insulation Mortar & One floor & $D<1 w k$ & Labor & Locator & In \& Out & RFID \\
\hline BE2570 & Cementitious Decks & Two floors & $D<1 w k$ & Equipment & Gate & In \& Out & RFID \\
\hline BE30A & Ceramic Tile (Floor) & One floor & $D<1 w k$ & Labor & Locator & In \& Out & RFID \\
\hline BE30B & Stone Tile & One floor & $D<1 w k$ & Labor & Locator & In \& Out & RFID \\
\hline BE30C & Ceramic Tile (Wall) & One floor & $D<1 w k$ & Labor & Locator & Out & RFID \\
\hline BE35A & Stone Flooring (Exterior) & One floor & $D<1 w k$ & Labor & Locator & Out & RFID \\
\hline BE35C & Stone Facing (Interior) & One floor & $D<1 w k$ & Labor & Locator & Out & RFID \\
\hline BE35D & Stone Facing (Exterior) & One floor & $D<1 w k$ & Labor & Locator & $\&$ Out & RFID \\
\hline $\mathrm{BE} 35 \mathrm{H}$ & Stone Jams and Sills & One building & $D<1 w k$ & Labor & Locator & In \& Out & RFID \\
\hline BE35K & Metal Truss & One floor & $D<1 w k$ & Labor & Locator & In \& Out & RFID \\
\hline BE40A & Stainless Steel Handrails & A stairwell & $D<1 w k$ & Labor & Locator & In \& Out & RFID \\
\hline BE40D & Gratings and Trenches & A section & $\mathrm{D}<1 \mathrm{wk}$ & Material & Locator & In \& Out & RFID \\
\hline BE40E & Aluminum Metal Fabrication & Project & $1 w k \leq D<2$ & All & N/A & Image & Manual \\
\hline BE40F & Aluminum Ceiling & Project & $D<1$ wk & Document & $\mathrm{N} / \mathrm{A}$ & Quantity & Report \\
\hline BE40G & Fan Coil Unit Covers & One floor & $\mathrm{D}<1 \mathrm{wk}$ & Labor & Locator & In \& Out & RFID \\
\hline $\mathrm{BE} 40 \mathrm{H}$ & Miscellaneous Metalwork & One building & $2 w k \leq D<1$ & Document & N/A & Quantity & Report \\
\hline BE5005 & Steel Doors & Project & $2 w k \leq D<1$ & Labor & Locator & In \& Out & RFID \\
\hline BE5010 & Stainless Steel Doors & Project & $D<1 w k$ & Labor & Locator & Out & RFID \\
\hline BE5015 & Aluminum Windows & Project & $2 w k \leq D<1$ & Labor & Locator & Out & RFID \\
\hline BE5030 & Hardware & Project & $2 w k \leq D<1$ & Document & N/A & Quantity & Report \\
\hline BE55A & Glazing (Interior) & Project & $2 w k \leq D<1$ & Document & N/A & Quantity & Report \\
\hline BE55B & Glazing (Exterior) & Project & $2 w k \leq D<1$ & All & $\mathrm{N} / \mathrm{A}$ & Image & Manual \\
\hline BE60A & Painting (Interior) & Three floors & $2 w k \leq D<1$ & Labor & Locator & In \& Out & RFID \\
\hline BE60B & Painting (Exterior) & Project & $1 w k \leq D<2$ & All & N/A & Image & Manual \\
\hline BE60C & Painting (Misc) & Project & $1 w k \leq D<2$ & Document & N/A & Quantity & Report \\
\hline BE65A & Resilient Flooring & One floor & $D<i w k$ & Labor & Locator & In \& Out & RFID \\
\hline BE65B & Access Flooring & Project & $D<1 w k$ & Document & N/A & Quantity & Report \\
\hline BE65C & OA Flooring & Project & $\mathrm{D}<1 \mathrm{wk}$ & Document & $\mathrm{N} / \mathrm{A}$ & antity & Report \\
\hline BE65D & System Furniture & Project & $2 w k \leq D<1$ & Document & $\mathrm{N} / \mathrm{A}$ & Quantity & Report \\
\hline BE65E & Compartments and Cubicles & Project & $D<1 w k$ & Document & N/A & Quantity & Report \\
\hline BE65F & Ceiling & One floor & $1 w k \leq D<2$ & Labor & Locator & In \& Out & RFID \\
\hline BE65G & Gypsum Board Assemblies & One floor & $1 w k \leq D<2$ & Labor & Locator & In \& Out & RFID \\
\hline BE70A & Cementitious Fireproofing & One floor & $D<\dot{1} w k$ & Labor & Locator & In \& Out & RFID \\
\hline BE70B & Acoustical Wall & One floor & $D<1 w k$ & Labor & Locator & In \& Out & RFID \\
\hline BE70C & Building Insulation & One floor & $1 w k \leq D<2$ & Labor & Locator & In \& Out & RFID \\
\hline BE75 & Miscellaneous Finishing & Project & $\mathrm{D}<1 \mathrm{wk}$ & Document & N/A & Quantity & Report \\
\hline BE8010 & Planting & Project & $2 w k \leq D<1$ & All & N/A & Image & Manual \\
\hline BE8020 & Pavement \& Landscape & Project & $2 w k \leq D<1$ & All & $\mathrm{N} / \mathrm{A}$ & Image & Manual \\
\hline
\end{tabular}

Columns (a), (b), (c), (d) are from Jung and Kang (2007) ${ }^{1}$, and columns (e), (f), (g), (h) from Kang and Jung (2012) ${ }^{4}$ 
Dat Applications for Multiple Work Packages The result from steps one through three in Figure 2 is listed in Table 1. The case-project has sixty-one PMPs (work packages without locators, e.g. concrete) and 233 network scheduling activities (work packages with locators, e.g. $1^{\text {st }}$ floor concrete) ${ }^{1}$. Automated data acquisition methods for these sixtyone PMPs are illustrated in the Column (e) through (h) of Table 1 and in Figure 3.

It is noteworthy that 'in and out' information of 'labors' into a locator of 'floor (story)' is most often used method among these sixty-one PMPs. Thirtyfour PMPs out of sixty-one (55.6\%) have the exactly same DAT requirements; The common conditions are 'labor' as object (column e), 'locator' as range (column f), 'in and out' as data type (column g), and 'RFID' as DAT type (column h).

Therefore, the thirty-four activities under these common conditions are chosen in this study as being the most promising area for repeatedly using the same sensing technology. For this chosen type of activities, several different DAT candidates are examined including RFID active, RFID passive, and simple motion sensors.

While the RFID applications can collect precise and rich information, it has a couple of drawbacks. For example, in this case-project, every worker should carry a RFID tag whenever he or she is in the job sit. Another point is that a RFID reader should be place on every floor in order to collect 'locator-specific' information. The cost for RFID reader on every floor (or locator) is also relatively high.

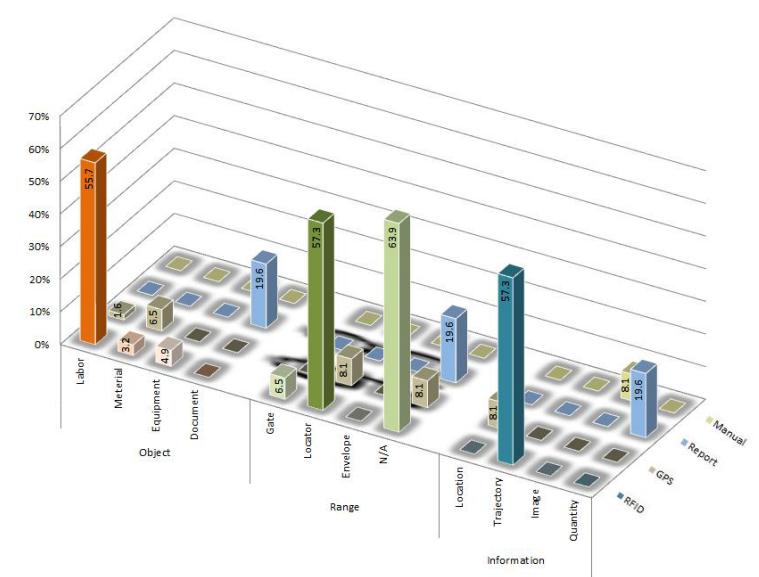

Fig. 3. Automated Progress Measurement Patterns of Case-Project (Kang \& Jung 2012)

\section{MOTION SENSORS FOR LABOR MONITORING}

In order to develop economically effective and feasible DAT applications, several different options for the thirty-four work packages (measuring 'in and out' information of 'labors' into a locator of 'floor'), were analyzed.
Again, even though RFID or GPS is a good solution, it requires every single laborer carry one device. Under harsh out-door construction job site environment, this requirement is a big burden in terms of cost, maintenance effort, and even workers' productivity.

Finally, using motion sensors was examined as a solution. A good example is the sensor used in a lighting fixture for energy savings. Motion sensors are used everywhere for automatically switching on and off the lightings. Advantages of motion sensors include no need to carry a device, the low cost, easiness to acquire, and simplicity of device. On the other hand, the most important drawback is that it cannot identify individual, crew, or trade.

In order to solve this problem, requirements for using motion sensors for progress measurement are studied as listed in Table 2.

Initially, the proposed motion sensor system needs labor activity information. In other words, daily distribution of laborers for all thirty-four activities should be calculated for each locator (i.e. floor in this caseproject). After calculating the labor distribution, one motion sensor needs to be installed to collect movement of labors within that locator. Next step is to transmit those data to a receiver. Finally, the data received will be compared against planned data in order to determine the completion of a work package based on a daily time scale.

Table 2 summarizes the advantages, drawbacks, requirements for overcome the drawbacks, and logical sequence of proposed 'motion sensor based progress measurement system'.

Table 2. Motion sensors as APMM DAT

\begin{tabular}{|c|c|}
\hline \multirow{4}{*}{ Advantages } & A1 No need to carry a device (laborer) \\
\hline & A2 Low cost \\
\hline & A3 Easiness to acquire \\
\hline & A4 Simplicity of device \\
\hline \multirow{2}{*}{ Drawbacks } & D1 No information of individual \& trade \\
\hline & D2 No information of the exact location \\
\hline \multirow{4}{*}{$\begin{array}{c}\text { Require- } \\
\text { ments } \\
\text { as DAT }\end{array}$} & R1 Prerequisite labor activity information \\
\hline & R2 One sensor required for each locator \\
\hline & R3 Transmitter required for each locator \\
\hline & R4 Algorithm for progress measurement \\
\hline \multirow{5}{*}{$\begin{array}{c}\text { Systems } \\
\text { Develop- } \\
\text { ment }\end{array}$} & S1 Calculating daily labor distribution \\
\hline & S2 Analyze distribution patterns \\
\hline & S3 Collect motion data \\
\hline & S4 Compare motion data against S2 \\
\hline & S5 Determine progress \\
\hline
\end{tabular}




\section{ANALYZING LABOR DISTRIBUTION FOR APMM}

This study is on-going and still under further development. By using the case-project, technical feasibility of proposed system is examined.

For the first step of systems development in Table 2 (S1 'calculating daily labor distribution'), labor distribution was calculated. For the purpose of initial analysis and easier understanding, six activities from thirty-four work packages are selected and modeled in Table 3 and Figure 4. Six activities include formwork (BC3020 in Table 1), reinforcing steel (BC3030), concrete (BC3010), brick masonry (BC60A), plastering (BE2505), and ceramic tile (BE30A).

A CPM schedule was developed for these activities for a ten story building. A linear scheduling method (LSM) was also used to facilitate effective resource (labor) leveling and sequencing. The values of standard crew mix and daily output are applied to calculate the required number of laborers for the activities as described in Table 3 (e.g. 13 laborers are required to complete concrete work for one floor). Finally, number of laborers per day and duration for each activity are calculated and summarized by locator (floor) as well as by project total (Figure 4 and Figure 5).

Table 3. Productivity and Required Labor (per locator)

\begin{tabular}{|c|c|c|c|c|c|c|}
\hline ID & $\begin{array}{l}\text { 응 } \\
\text { ల్ } \\
\text { ஸे }\end{array}$ & $\begin{array}{l}\text { ণ } \\
\text { ర్ల } \\
\text { ల్ }\end{array}$ & $\begin{array}{l}\text { ్ } \\
\text { ర్ల } \\
\text { ర్ల }\end{array}$ & 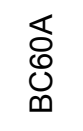 & 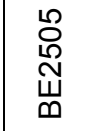 & 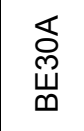 \\
\hline PMP & $\begin{array}{l}\stackrel{ \pm}{0} \\
\frac{1}{0} \\
\check{0} \\
0\end{array}$ & 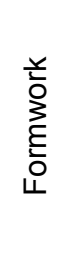 & 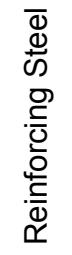 & 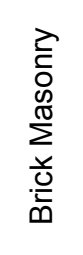 & 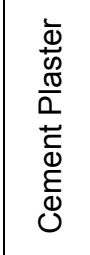 & 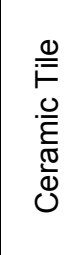 \\
\hline Unit & $\stackrel{\mathscr{E}}{E}$ & है & ఫิ & $\begin{array}{l}\mathbb{1} \\
8 \\
8\end{array}$ & हี & है \\
\hline Quantity & 180 & 666 & 337 & 46 & 272 & 16 \\
\hline $\begin{array}{c}\text { Crew Size } \\
\text { (No. of Laborer) }\end{array}$ & 13 & 6 & 8 & 5 & 6 & 2 \\
\hline $\begin{array}{l}\text { Labor Hours } \\
\text { (Per unit) }\end{array}$ & $\begin{array}{c}0.0 \\
7\end{array}$ & $\begin{array}{c}0.1 \\
4\end{array}$ & $\begin{array}{c}0.2 \\
6\end{array}$ & $\begin{array}{c}2.2 \\
0\end{array}$ & $\begin{array}{c}0.2 \\
6\end{array}$ & $\begin{array}{c}0.3 \\
8\end{array}$ \\
\hline Total Labor & 13 & 94 & 88 & 101 & 71 & 6 \\
\hline $\begin{array}{l}\text { No. of Crews } \\
\text { (per locator) }\end{array}$ & 1.0 & $\begin{array}{c}15 . \\
7\end{array}$ & $\begin{array}{c}11 . \\
0\end{array}$ & $\begin{array}{c}20 . \\
2\end{array}$ & $\begin{array}{c}11 . \\
8\end{array}$ & 3.1 \\
\hline $\begin{array}{l}\text { No. of Crews } \\
\text { (per day) }\end{array}$ & 1 & 5 & 6 & 5 & 4 & 3 \\
\hline $\begin{array}{l}\text { Duration } \\
\text { (Day) }\end{array}$ & 1.0 & 3.1 & 1.8 & 4.0 & 2.9 & 1.0 \\
\hline Activity Profile & \multicolumn{3}{|c|}{ Uneven } & Even & Even & Even \\
\hline
\end{tabular}

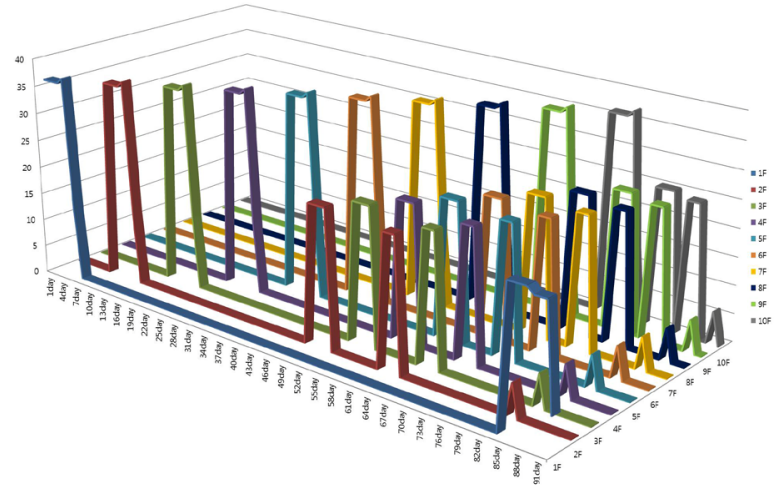

Fig. 4. Labor Distribution by Locator (for each floor)

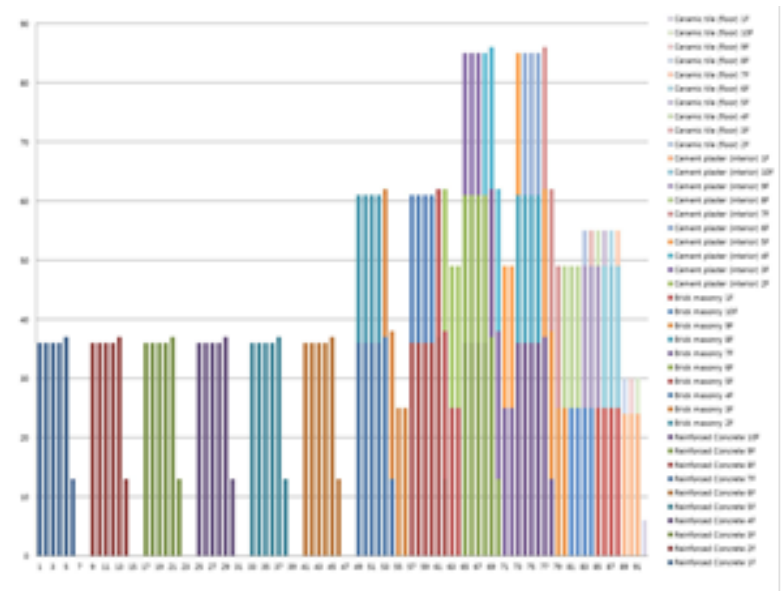

Fig. 5. Total Labor Distribution (for ten floors)

\section{IDENTIFYING LABOR DISTRIBUTION PATTERNS}

Figure 5 shows that there are two different major factors characterizing labor distributions of CPM activities. One is whether an activity requires lag time between floors within the same PMP (discrete, D) or not (continuous, C). Concrete is the case; It requires curing between floors. The second pattern is the shape of labor distribution curve within an activity. For example, while concrete (including formwork and reinforcing steel) has an uneven (U) distribution, brick masonry has an even (E) distribution throughout the activity's entire duration.

These two factors give four combinations, discrete uneven (D-U), discrete even (D-E), continuous uneven $(C-U)$, and continuous even (C-E). In Figure 4 and 5 , concrete work is discrete and uneven (D-U), and brick masonry, cement plaster, and ceramic tile are continuous even (C-E) as listed in Table 4.

These patterns provide indirect clues for progress measurement. For example, because the concrete work has uneven distribution, decrease of labor members on $6^{\text {th }}$ day for each floor indicates that concrete pouring is started on that floor. Decrease of labor members by 13 on $7^{\text {th }}$ day means concrete pouring was completed and curing has been started. 
Table 4. Patterns of Labor Distribution between Locator

\begin{tabular}{|c|c|c|}
\hline Pattern & Inference & Example \\
\hline D-U & $\begin{array}{c}\text { Partial completion \& } \\
\text { Completion detected }\end{array}$ & $\begin{array}{c}\text { Concrete } \\
\text { (w/ form \& re-bar) }\end{array}$ \\
\hline D-E & Completion detected & Steel structure \\
\hline C-U & $\begin{array}{c}\text { Partial completion \& } \\
\text { Completion detected }\end{array}$ & $\begin{array}{c}\text { Stone cladding } \\
\text { (w/ frame) }\end{array}$ \\
\hline C-E & Completion detected & Brick Masonry \\
\hline
\end{tabular}

By combining and comparing data from planned distribution of each floor (Figure 4), planned distribution of all floors (Figure 5), and data from actual distribution on the job site, completions of activities can be automatically measured.

\section{Motion SENSOR BASEd APPM SYSTEM}

By using the progress measurement algorithm introduced in previous chapters, a motion sensor based APPM system is proposed.

The system is composed of three modules. First module is the DAT module. A motion sensor is attached to a RFID active device. This module is installed at every locator (floor in this case-project). Therefore, for a ten story building, ten RFID actives are required. However, this module has only one RFID reader. Transmission between ten RFID actives and one reader is designed to use wireless channels for easier maintenance on the job site.

The second module includes algorithms for automated pattern recognition. Data from planned schedule is converted to daily labor distribution as depicted in Figure 4 and 5.

Final module is to input engineers' final decision. Automatically generated progress information will be summarized and reported for engineers' approval. This process should be performed on a daily basis. The prototype system is under development and is under patent pending.

\section{CONCLUSIONS}

Progress measurement is one of the most critical tasks for successful project performance management. Maintaining accurate and timely progress information demands extra managerial overhead cost. In order to solve this problem, rigorous research efforts have been exerted to automate the data collection process by using sensors.

Nevertheless, previous researches have mainly focused on a specific DAT or on the limited construction tasks. In this context, the purpose of this paper was to propose a methodology for integrated utilization of DATs by repeatedly applying the same sensors to multiple work items

Based on evaluations of DATs and work packages of a case-project, candidates for the repeated applications were identified. Motion sensor is selected as being the low cost DAT, and algorithms for implementing the proposed application were developed.

It is found that $56 \%$ of work packages can be measured by using the same sensors repeatedly. Another notion is that this paper tried to fully automate the progress measurement of an entire construction project instead of limited work packages.

It is found that the most promising area for automated progress measurement and management (APMM) is to deploy 'simplified and low-cost sensors' for monitoring the 'entrance and exit' of 'labors' into a locator of 'floor (story)' level for a building construction.

\section{ACKNOWLEDGEMENTS}

This study was supported by the Korean Ministry of Education, Science, and Technology (MEST) under Grant No. 2009-0074881 (Automated Progress Measurement and Management) and 2011-0022900 (Knowledge-based BIM Applications). The support is gratefully acknowledged.

\section{References}

1. Jung, Y., Kang, S., "Knowledge-Based Standard Progress Measurement for Integrated Cost and Schedule Performance Control", Journal of Construction Engineering and Management, ASCE, Vol. 133(1), pp. 10-21, 2007.

2. Jung, Y., Lee, S., "Automated Progress Measurement and Management in Construction: Variables for Theory and Implementation", Proceedings of the International Conference on Computing in Civil and Building Engineering (ICCCBE 2010), Nottingham, UK, University of Nottingham Press, Paper 117, p. 233, 2010.

3. Jung, Y., Woo, S., "Flexible Work Breakdown Structure for Integrated Cost and Schedule Control", Journal of Construction Engineering and Management, Vol. 130(5), pp. 616-625, 2004.

4. Kang, S., Jung, Y., "Data Acquisition Technology (DAT) Selection Algorithm for Automated Progress Measurement and Management", Korean Journal of Construction Engineering and Management, KICEM, Vol. 13(1), pp. 77-86, 2012.

5. Navon, R., Goldschmidt, E., "Can Labor Inputs be Measured and Controlled Automatically?", Journal of Construction Engineering and Management, ASCE, Vol. 129(4), pp. 437-445, 2003.

6. Navon, R., "Research in Automated Measurement of Project Performance Indicators", Automation in Construction, Vol. 16(2), pp. 176-188, 2007.

7. Sacks, R., Navon, R., Goldschmidt, E., "Building Project Model Support for Automated Labor Monitoring", Journal of Computing in Civil Engineering, ASCE, Vol. 17(1), pp. 19-27, 2003.

8. Seo, K., Park, J., Jung, Y., "Effective Areas for DAT Utilization in Construction Projects", Korean Journal of Construction Engineering and Management, KICEM, Vol. 11(2), pp. 15-24, 2010. 